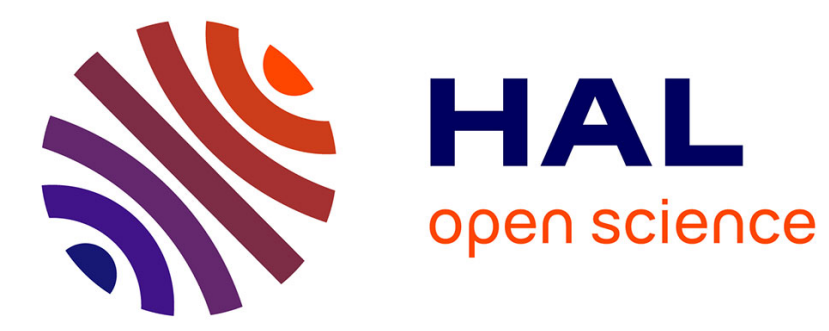

\title{
Sequence similarities between viroids and human microRNAs
}

Jessica grace Bengone-Abogourin, Nisrine Chelkha, Eric Verdin, Philippe Colson

\section{To cite this version:}

Jessica grace Bengone-Abogourin, Nisrine Chelkha, Eric Verdin, Philippe Colson. Sequence similarities between viroids and human microRNAs. Intervirology, 2020, 62 (5-6), pp.227-234. 10.1159/000509212 . hal-02914619

\section{HAL Id: hal-02914619 \\ https: / hal.inrae.fr/hal-02914619}

Submitted on 23 Feb 2022

HAL is a multi-disciplinary open access archive for the deposit and dissemination of scientific research documents, whether they are published or not. The documents may come from teaching and research institutions in France or abroad, or from public or private research centers.
L'archive ouverte pluridisciplinaire HAL, est destinée au dépôt et à la diffusion de documents scientifiques de niveau recherche, publiés ou non, émanant des établissements d'enseignement et de recherche français ou étrangers, des laboratoires publics ou privés.

\section{(ㅇ)(1) $\$$}

Distributed under a Creative Commons Attribution - NonCommercial - NoDerivatives| 4.0 


\title{
Sequence Similarities between Viroids and Human MicroRNAs
}

\author{
Jessica Grace Bengone-Abogourin ${ }^{\mathrm{a}}$ Nisrine Chelkha ${ }^{\mathrm{a}}$ Eric Verdin ${ }^{\mathrm{c}}$ \\ Philippe Colson ${ }^{a, b}$ \\ ${ }^{a}$ Aix-Marseille University, Institut de Recherche pour le Développement (IRD), Assistance Publique - \\ Hôpitaux de Marseille (AP-HM), Microbes Evolution Phylogeny and Infections (MEPHI), Marseille, France; \\ bIHU Méditerranée Infection, Marseille, France; CINRA, UR407, Unité de Pathologie Végétale, \\ Montfavet, France
}

\section{Keywords}

Viroid - microRNA $\cdot$ RNA interference $\cdot$ Human · Plants .

Messenger RNA

\begin{abstract}
Viroids are minute unencapsidated non-coding circular RNAs known to be present and to cause diseases only in plants. Infections were associated with the occurrence of specific single-stranded RNAs similar in size to miRNAs and endogenous small interfering RNAs, and viroid pathogenicity is suspected to occur through RNA interference. We looked for sequence similarities between viroids and the seed region of human microRNAs (hsa-miRNAs). Viroid genomes were retrieved from GenBank and mature hsa-miRNAs were retrieved from miRBase. Two hundred 300-nucleotide-long sequences were randomly generated as controls. BLAST searches were performed using viroids as queries and hsa-miRNAs as subjects with relaxed parameters, and matches involving hsa-miRNA seed regions were considered. A total of 81,021 matches were found, and 1,501 that showed $100 \%$ identity with whole hsa-miRNA seed regions were selected. The most frequent matches involved Chrysanthemum stunt viroid or Hop stunt viroid species with hsamiR-4286, in 365 and 207 cases, respectively. Three hsa-mi-
\end{abstract}

RNAs (miR-4286, miR-6808-5p, and miR-3622a-3p) were involved in $47 \%$ of all matches between viroids and hsa-miRNAs. Taken together, these findings warrant further investigation on the potential of viroids and their derived small RNAs to cross kingdoms and interact with nucleic acids in humans.

(c) 2020 S. Karger AG, Basel

\section{Introduction}

Very few connections have been made between vegetal and animal pathogens, which are studied by distinct researchers [1]. Thus, viroids are very particular entities that are pathogenic for crop plants and have only been studied in plants $[2,3]$. They are minute (246-401 nucleotides [nt] long) unencapsidated non-coding circular RNAs endowed with autonomous replication $[3,4]$. They are highly stable due to high levels of intrasequence complementarities [5]. The mechanisms by which viroids cause diseases in plants are suspected to involve RNA interference, and RNA interference machineries from host cells $[6,7]$. Several structural and functional similarities have been highlighted between viroids and pre-microRNAs (pre-miRNAs), which are hairpin-shaped stem-

\section{KARGER}

(c) 2020 S. Karger AG, Basel

karger@karger.com

www.karger.com/int
Philippe Colson

Virology, MEPHI

IHU Méditerranée Infection

19-21 Boulevard Jean Moulin, FR-13005 Marseille (France)

philippe.colson@univ-amu.fr 


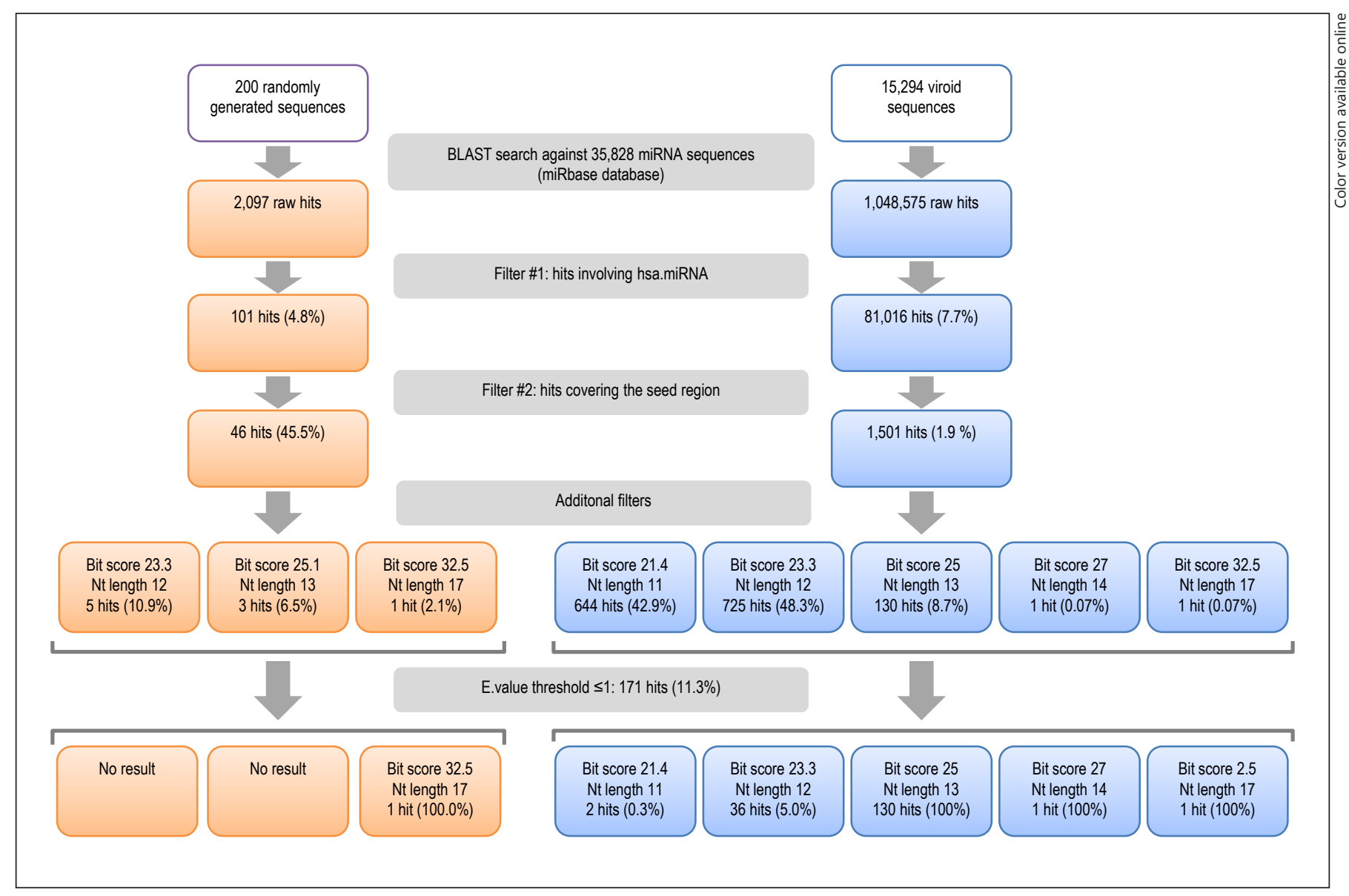

Fig. 1. Flowchart of the BLAST searches and matches for miRNA against all generated random sequences and all the viroid sequences.

loop double-stranded RNA precursors of miRNA [8]. This is for instance the case between Potato spindle tuber viroid and human pre-miRNA-146a. In their mature form, miRNAs are non-coding regulatory sequences that are small, 18-25 nt in size, and interfere with host target genes in cells from plants, insects, nematodes, and vertebrates, including humans $[9,10]$. A nucleotide motif located at miRNA positions 2-7 or 8 , called the "seed region," plays an active role in this RNA interference [11]. It is complementary to the $3^{\prime}$ - or $5^{\prime}$-untranslated regions (UTR) that are conserved regions of host messenger RNAs (mRNAs) [10, 12]. It was shown that a perfect complementarity between this seed region and its target can induce RNA silencing in mammals [13]. Moreover, miRNA seed-matching regions have been described as being conserved in multiple mRNAs from mammals, including humans $[10,14]$. Here, we sought similarities between viroids and the seed region of mature human (hsa, for Homo sapiens) miRNAs.

\section{Materials and Methods}

We first retrieved all viroid genomes available from the NCBI GenBank nucleotide sequence database (https://www.ncbi.nlm.nih. gov) and all available mature miRNA sequences from the miRBase database (www.mirbase.org) [15]. In addition, through the RANDNA tool [16], we generated 200 random sequences with a size of 300 nt, similar to that of viroids, to use as controls. They consisted of 5 groups of 40 sequences with a $\mathrm{G}+\mathrm{C}$ content of $40,45,50,55$, and $60 \%$, chosen to cover the range of $\mathrm{G}+\mathrm{C}$-contents found in viroids. We performed BLAST searches using viroid sequences as queries and all mature miRNA sequences as subjects, with relaxed parameters including 4 as word size, 1,000 as e-value threshold, and no filter. The ten best BLAST results were thereafter filtered by keeping only viroids matching with mature hsa-miRNAs. The same protocol was used by handling the random sequences. BLAST results were sorted based primarily on a match involving the seed region of hsamiRNAs (2-7 nt), as well as thresholds for the BLAST scores, the length of the sequence alignments, the percentage of identity between viroids and mature hsa-miRNAs, and the e-value (Fig. 1). Finally, information on hsa-miRNAs whose seed region matched with viroid RNAs according to our criteria were searched for through the miRBase database and the NCBI PubMed database (https://www. 
Table 1. Top 31 most frequent matches (with a frequency $\geq 5$ ) between viroids and seed regions of hsa-miRNAs

\begin{tabular}{|c|c|c|c|c|}
\hline No. & Acronyms & Viroid species & hsa-miRNA & Frequency \\
\hline 1. & CSVd & Chrysanthemum stunt viroid & hsa-miR-4286 & 365 \\
\hline 2. & HSVd & Hop stunt viroid & hsa-miR-6808-5p & 207 \\
\hline 3. & PTSVd & Potato spindle tuber viroid & hsa-miR-3622a-3p & 102 \\
\hline 4. & HSVd & Hop stunt viroid & hsa-miR-4441 & 65 \\
\hline 5. & CEVd & Citrus exocortis viroid & hsa-miR-9901 & 51 \\
\hline 6. & PLMVd & Peach latent mosaic viroid & hsa-miR-3689d & 43 \\
\hline 7. & PLMVd & Peach latent mosaic viroid & hsa-miR-6799-5p & 43 \\
\hline 8. & PLMVd & Peach latent mosaic viroid & hsa-miR-6825-5p & 43 \\
\hline 9. & CDVd & Citrus dwarfing viroid & hsa-miR-9898 & 37 \\
\hline 10. & CLVd & Columnea latent viroid & hsa-miR-4725-5p & 30 \\
\hline 11. & HSVd & Hop stunt viroid & hsa-miR-1207-5p & 26 \\
\hline 12. & HSVd & Hop stunt viroid & hsa-miR-4756-5p & 26 \\
\hline 13. & PCFVd & Pepper chat fruit viroid & hsa-miR-4740-3p & 26 \\
\hline 14. & PCFVd & Pepper chat fruit viroid & hsa-miR-6836-3p & 25 \\
\hline 15. & ADFVd & Apple dimple fruit viroid & hsa-miR-9898 & 22 \\
\hline 16. & CEVd & Citrus exocortis viroid & hsa-miR-8072 & 17 \\
\hline 17. & CEVd & Citrus exocortis viroid & hsa-miR-4649-3p & 16 \\
\hline 18. & ASSVd & Apple scar skin viroid & hsa-miR-6775-3p & 10 \\
\hline 19. & GYSVd & Grapevine yellow speckle viroid & hsa-miR-1253 & 9 \\
\hline 20. & GYSVd & Grapevine yellow speckle viroid & hsa-miR-6878-3p & 9 \\
\hline 21. & ELVd & Eggplant latent viroid & hsa-miR-514b-3p & 8 \\
\hline 22. & PSTVd & Potato spindle tuber viroid & hsa-miR-3074-5p & 8 \\
\hline 23. & CDVd & Citrus dwarfing viroid & hsa-miR-6758-5p & 7 \\
\hline 24. & CEVd & Citrus exocortis viroid & hsa-miR-6787-3p & 7 \\
\hline 25. & CBVd & Coleus blumei viroid & hsa-miR-191-5p & 7 \\
\hline 26. & MPVd & Mexican papita viroid & hsa-miR-3622a-3p & 7 \\
\hline 27. & PSTVd & Potato spindle tuber viroid & hsa-miR-4291 & 7 \\
\hline 28. & PSTVd & Potato spindle tuber viroid & hsa-miR-4649-5p & 7 \\
\hline 29. & HSVd & Hop stunt viroid & hsa-miR-6876-5p & 6 \\
\hline 30. & TMCVd & Tomato chlorotic dwarf viroid & hsa-miR-3622a-3p & 6 \\
\hline 31. & PCFVd & Pepper chat fruit viroid & hsa-miR-3682-5p & 5 \\
\hline
\end{tabular}

ncbi.nlm.nih.gov/pubmed). Nucleotide diversity at viroid regions matching with mature hsa-miRNA seed regions was represented using the WebLogo online tool version 2.8.2 [17]. Statistical analyses were performed with Openepi software (v.3.03a; http://www.openepi.com). Proportions were compared using $\chi^{2}$ or Fisher tests. $p<$ 0.05 was considered significant.

\section{Results}

A total of 15,294 viroid sequences were used as queries for BLAST searches against a database of 35,828 mature miRNAs. This generated 1,048,575 hits (Fig. 1). Of them, $81,021(7.7 \%)$ corresponded to matches between viroids and hsa-miRNA seed regions. After considering cases where viroid fragments were $100 \%$ similar to the whole hsa-miRNA seed region from its start (position 1 or 2), 1,501 hits $(1.9 \% ; 0.14 \%$ of the total number of hits) remained (online suppl. Table S1; for all online suppl. material, see www.karger.com/doi/10.1159/000509212). BLAST results were found to have an e value $<1$ in 170 (11.3\%) cases. Among these 1,501 hits, 644, 725, 130, 1, and 1 had a nucleotide alignment length of $11,12,13,14$, and $17 \mathrm{nt}$, respectively. The longest match (17 nt) involved Potato spindle tuber viroid strain DI285387_1_KR 1020130054489-A/33666 and hsa-miRNA-6774-5p, with a BLAST bit score of 32.5 . The second longest match (14 nt) was between Potato spindle tuber viroid strain A/2147 and hsa-miRNA-3145-5p (BLAST bit score of 27). After removing duplicates, 25 different viroid species were involved in matches with the seed region of 212 different hsa-miRNAs (Table 1). A same procedure was applied to the 200 random sequences of 300 nt used as controls for specificity assessment. BLAST searches using these sequences against the miRNA database generated 2,097 hits. Out of them, 101 (4.8\%) involved the whole seed region of several hsa-miRNAs with an identity of $100 \%$. Among 
Fig. 2. Chord diagram representing the frequency of matches between the 10 viroid species and hsa mature-miRNAs the most frequently involved in matches. Numbers on the inner circle indicate numbers of interactions between viroids and hsa-miRNAs.

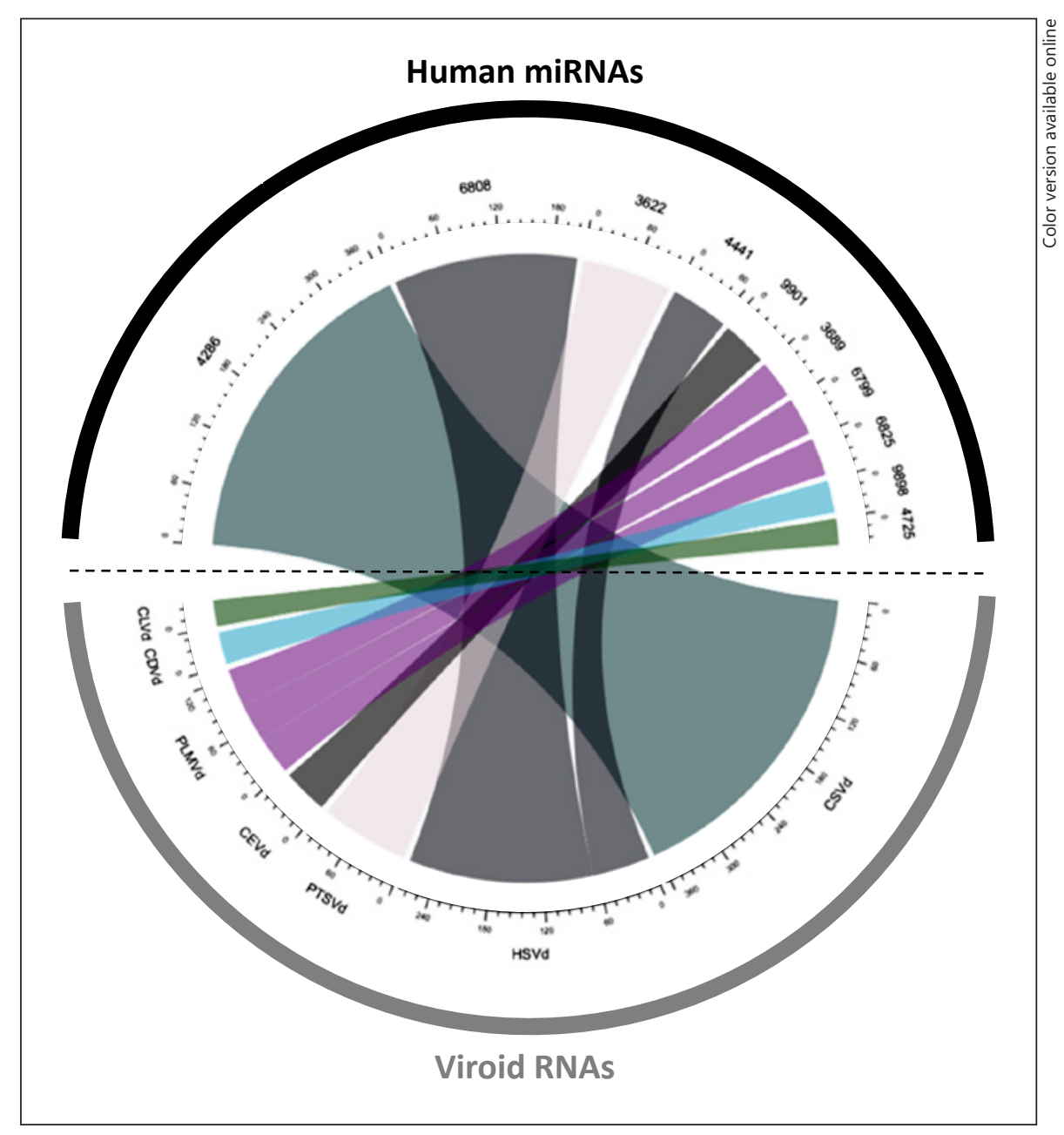

these 101 hits, 5, 3, and 1 had a nucleotide alignment length of 12,13 , and $17 \mathrm{nt}$, respectively. Hence, the proportion of these hits with an alignment length $\geq 12 \mathrm{nt}$ was higher for viroids than for controls ( 57 vs. $20 \%$; $p<1 \mathrm{e}-3$ ).

Overall, the most frequent matches involved Chrysanthemum stunt viroid or Hop stunt viroid species (online suppl. Fig. S1) with hsa-miR-4286, in 365 and 207 cases, respectively (Table 1). Potato spindle tuber viroid species matched 102 times with hsa-miR 3622. Nineteen of the 25 species of viroids for which fragments were found to match significantly with the seed region of hsa-miRNAs are known to infect fruits or vegetables that are common in human food, which suggests that humans can be exposed to them (online suppl. Table S2). The other viroids have been described to infect flowers, which may also allow contacts with humans. The 10 viroid species most frequently involved in the 1,501 significant matches with seed regions of hsa-miRNAs were implicated in almost all matches, and 5 of them - Chrysanthemum stunt viroid,
Hop stunt viroid, Potato spindle tuber viroid, Peach latent mosaic viroid, and Citrus exocortis viroid - represented $83 \%$ of all matches (online Suppl. Fig. S1). Moreover, matches between 7 different viroid species and 10 hsamiRNAs represented $66 \%$ of all matches (Fig. 2).

Thirteen hsa-miRNAs were found to match with $>1$ viroid species (online Suppl. Table S3). The 10 hsa-miRNAs whose seed regions most frequently matched with viroids were involved in $69 \%$ of all matches (online suppl. Fig. S2). Three hsa-miRNAs - miR-4286, miR-6808-5p, and miR-3622a-3p - were involved in almost half (47\%) of all matches. MiR-4286 upregulation was reported in various types of malignancies, including pancreatic cancer, glioma, esophageal adenocarcinoma, and melanoma $[18,19]$. MiR-6808 has been described as part of human splicing-derived miRNAs ("mirtrons") and was notably found to target the DVL1 gene, the dysregulation of which is associated with the progression of numerous cancers $[20,21]$. MiR-3622a-3p has been identified as significant- 
a

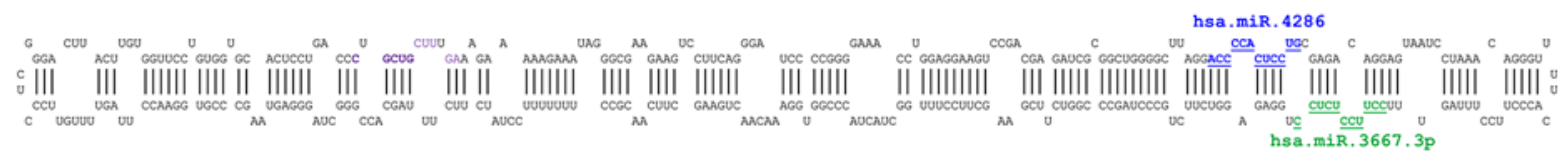

b

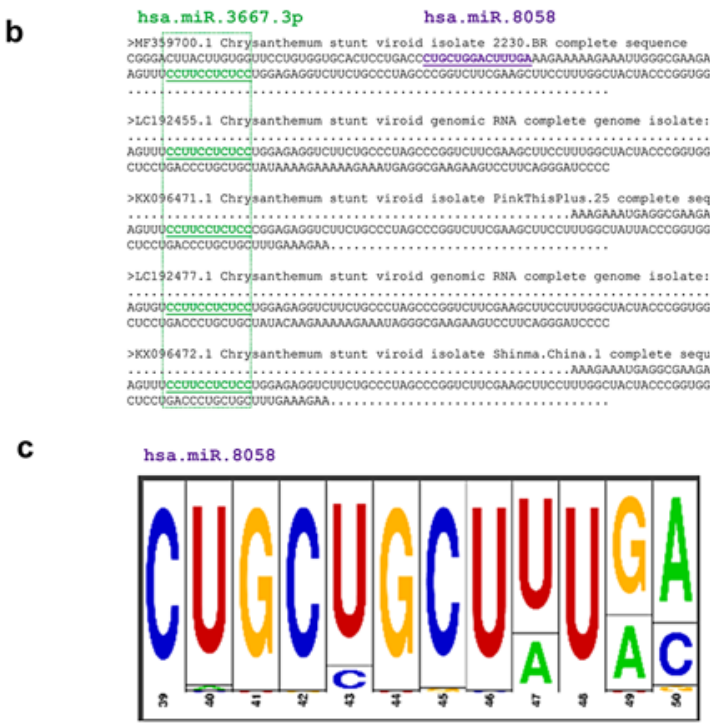

hsa.miR. 4286
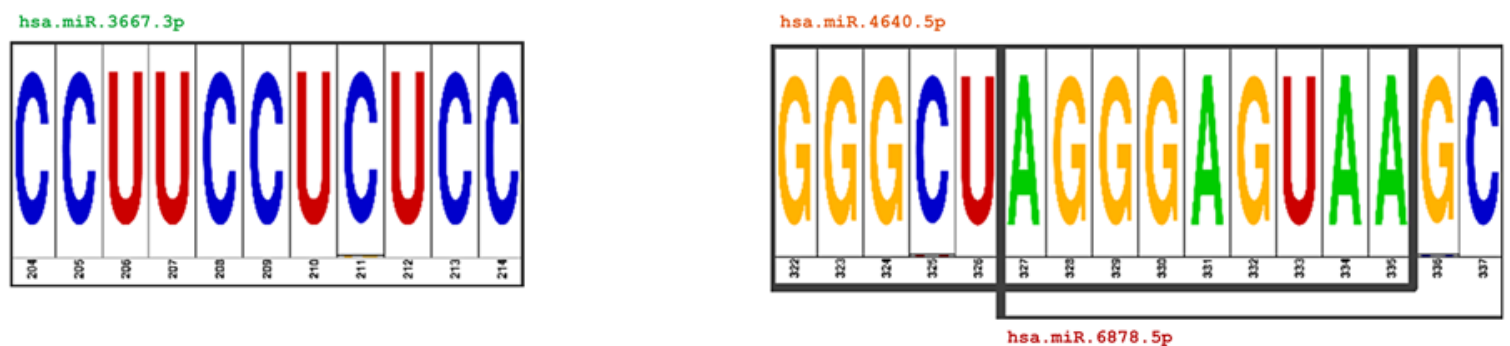

Fig. 3. Conservation in the genomes from different isolates of Chrysanthemum stunt viroid and Potato spindle tuber viroid species of the regions that matched with the seed regions of hsa-miRNAs. Conservation in the genomes from different isolates of Chrysanthemum stunt viroid and Potato spindle tuber viroid species of the regions that matched with the seed regions of hsa-miRNAs were represented on a viroid circularized genome (a, d), on alignments of 5 viroid sequences (b, e), and as sequence logos showing the consensus sequences corresponding only to viroid re-

ly expressed in patients suffering from bladder urothelial carcinoma and associated with longer survival times [22]. In addition, miR-4441, the fourth miRNA whose seed region most frequently matched with viroids, targets the human histone deacetylase 4 (HDAC4) gene that affects transcriptional regulation, cell cycle progression, and developmental events by altering or repressing access to tar-

Sequence Similarities between Viroids and Seed Regions of Human MicroRNAs gions matching hsa-miRNA seed regions $(\mathbf{c}, \mathbf{f})$. These sequence logos were built using the WebLogo online tool version 2.8.2 [17], with 91 Chrysanthemum stunt viroid sequences and 341 Potato spindle tuber viroid sequences that were downloaded from the NCBI GenBank nucleotide sequence database using viroid names and "complete" and "genome" as search terms, and that were directly alignable on their full length (see also online suppl. Fig. S3, S4 showing sequence logos for full-length viroids, and online suppl. Materials with viroid full-length sequence alignments).

(Figure continued on next page.)

get DNA promoters [23]. Finally, we analyzed the conservation of the regions that perfectly matched with the seed regions of hsa-miRNAs in the genomes of various viroid isolates from 2 species. We observed that these regions were either conserved or varied between viroid isolates in the genomes from Chrysanthemum stunt viroid and Potato spindle tuber viroid (Fig. 3). 
d

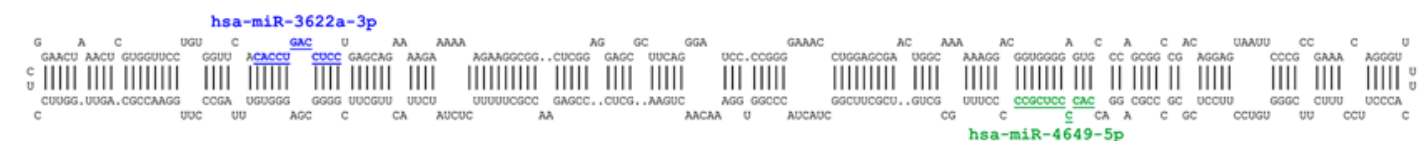

e

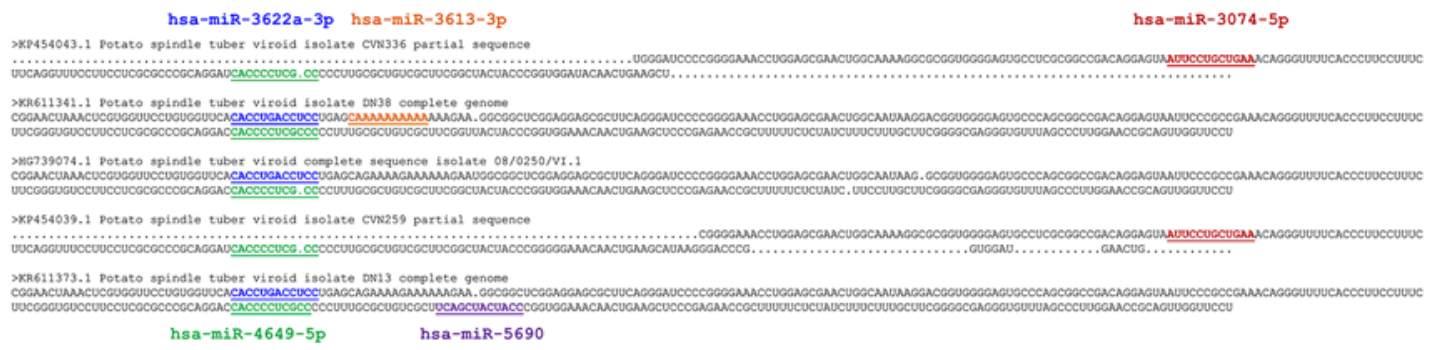

hsa-miR-4649-5p

hsa-miR-5690

f
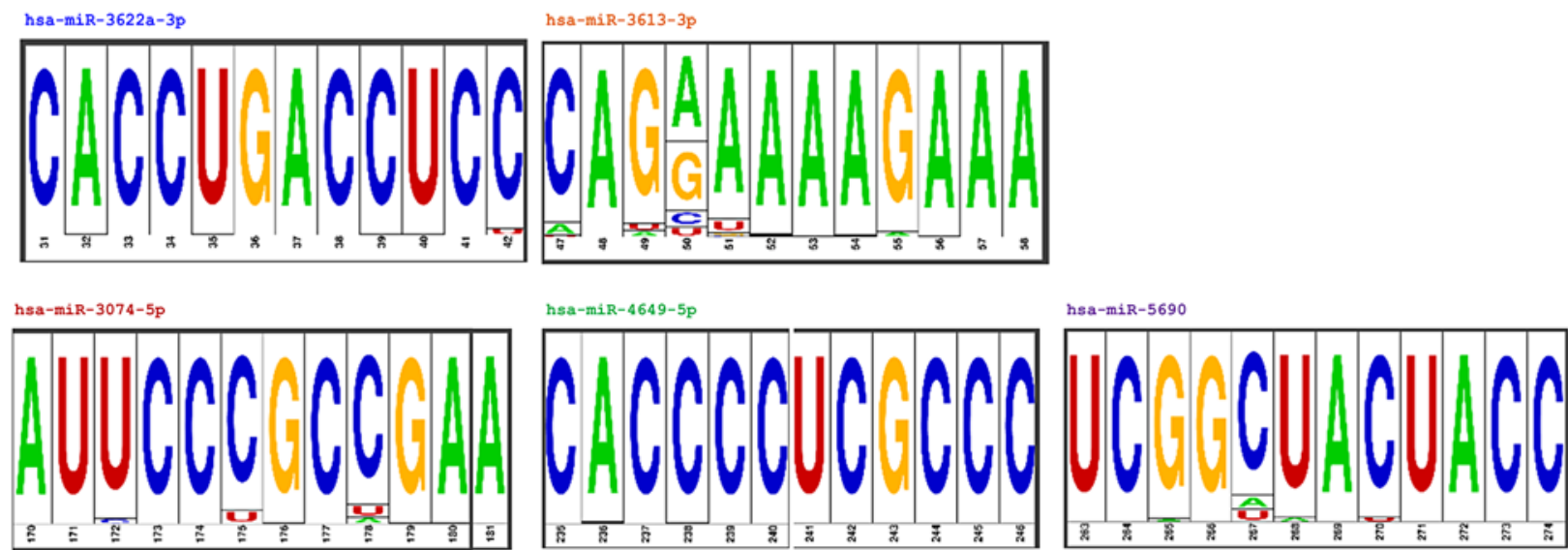

3

\section{Discussion}

Here, we describe for the first time $100 \%$ identity between several viroid fragments and the seed region that acts in the RNA interference process of various human miRNAs. Previously, cross-kingdom similarities were also noted between human miRNAs and plant virus genomes [12]. Virus-encoded microRNAs have been described or hypothesized to interact with host mRNAs [24, 25]. For instance, human cytomegalovirus-encodedmiR-UL112 was found to downregulate the major histocompatibility complex class I-related chain B gene expression during viral infection [24]. More recently, SARS$\mathrm{CoV}$-encoded small RNAs were suspected to contribute to the lung pathology associated with viral infection [26]. Viroids have stem-loop-like conformations as pri- and pre-miRNAs, the miRNA precursors [3,5]. Viroids and pri- and pre-miRNAs are both RNA unencapsidated enti- ties with non-coding properties that involve ribonuclease and dicer complexes to produce small RNA units [27,28]. As a matter of fact, viroid infection was recently associated with the appearance of specific single-stranded RNA, the size of which is similar to that of miRNAs and endogenous small interfering RNAs $[7,29]$. Thus, viroid-specific small RNAs comprised by 21-24 nt were detected by Northern blots in infected plants for Potato spindle tuber viroid [28, 30], Citrus exocortis viroid [31], and Peach latent mosaic viroid [32], while Potato spindle tuber viroid RNA was deemed to be opportunistic and suspected as capable of using different processing pathways in different hosts [33].

Viroids were not detected previously in humans but they could have been missed. Interestingly, although viroids were deemed to only replicate in higher plants, one of them (Avocado sunblotch viroid) was shown to be able to replicate in a cyanobacterium and in the yeast Saccha- 
romyces cerevisiae [33-35]. In addition, exogenous small RNAs such as miRNAs were shown to be capable of spreading between cells [36]. Moreover, it was demonstrated that the miRNA-168a from rice was present in the serum samples of Chinese individuals whose main diet was based on this plant, could bind to the low-density lipoprotein receptor adapter protein 1 (LDLRAP1) mRNA, and was able to downregulate its expression in hepatocytes [37].

Taken together, these findings question the potential of viroids and their derived small RNAs to cross kingdoms to interact with nucleic acids in humans. Viroids are prevalent in plants worldwide and could be ingested through consumption of fruits and vegetables. It can also be hypothesized that miRNA-like RNAs derived from these viroids can be either transferred from plants to humans or processed from viroids in human cells, and they could theoretically interact with human mRNAs. Further investigation is warranted to search for the presence of viroids in humans and test for their effect on mammalian cells in vitro.

\section{Statement of Ethics}

Not applicable: only bioinformatic analyses on sequences already available in databases were performed.

\section{Disclosure Statement}

The authors have no conflicts of interest to declare.

\section{Funding Sources}

This research work was supported by the French Government under the "Investments for the Future" program managed by the National Agency for Research (ANR), Méditerranée-Infection 10IAHU-03, and was also supported by Région Provence Alpes Côte d'Azur and European funding FEDER PRIMMI (Fonds Européen de Développement Régional - Plateformes de Recherche et d'Innovation Mutualisées Méditerranée Infection). Mrs. Jessica Grace Bengone Abogourin received a grant from the IHU Méditerranée Infection foundation.

\section{Author Contributions}

Conceptualization: P.C. Methodology: P.C., J.G.B.-A., N.C. Analysis: J.G.B.-A., P.C., N.C., E.V. Writing - original draft preparation: J.G.B.-A., P.C. Writing - review and editing: P.C., J.G.B.-A., E.V.

\section{References}

1 Balique F, Lecoq H, Raoult D, Colson P. Can plant viruses cross the kingdom border and be pathogenic to humans? Viruses. 2015 Apr; 7(4):2074-98.

2 Gago-Zachert S. Viroids, infectious long noncoding RNAs with autonomous replication. Virus Res. 2016 Jan;212:12-24.

3 Flores R, Hernández C, Martínez de Alba AE, Daròs JA, Di Serio F. Viroids and viroid-host interactions. Annu Rev Phytopathol. 2005; 43(1):117-39.

4 Diener TO. Viroids and the nature of viroid diseases. Arch Virol Suppl. 1999;15:203-20.

5 Seligmann H, Raoult D. Unifying view of stem-loop hairpin RNA as origin of current and ancient parasitic and non-parasitic RNAs, including in giant viruses. Curr Opin Microbiol. 2016 Jun;31:1-8.

6 Navarro B, Gisel A, Rodio ME, Delgado S, Flores R, Di Serio F. Viroids: how to infect a host and cause disease without encoding proteins. Biochimie. 2012 Jul;94(7):1474-80.

7 Hammann C, Steger G. Viroid-specific small RNA in plant disease. RNA Biol. 2012 Jun; 9(6):809-19.

8 Hill JM, Lukiw WJ. Comparing miRNAs and viroids; highly conserved molecular mechanisms for the transmission of genetic information. Front Cell Neurosci. 2014 Feb;8:45.

9 Zeng J, Gupta VK, Jiang Y, Yang B, Gong L, Zhu H: Cross-kingdom small RNAs among animals, plants and microbes. Cells. 2019;8:371.
10 Friedman RC, Farh KK, Burge CB, Bartel DP Most mammalian mRNAs are conserved targets of microRNAs. Genome Res. 2009 Jan; 19(1):92-105

11 Lambert NJ, Gu SG, Zahler AM. The conformation of microRNA seed regions in native microRNPs is prearranged for presentation to mRNA targets. Nucleic Acids Res. 2011 Jun; 39(11):4827-35.

12 Rebolledo-Mendez JD, Vaishnav RA, Cooper NG, Friedland RP. Cross-kingdom sequence similarities between human micro-RNAs and plant viruses. Commun Integr Biol. 2013 Sep; 6(5):e24951.

13 Lewis BP, Burge CB, Bartel DP. Conserved seed pairing, often flanked by adenosines, indicates that thousands of human genes are microRNA targets. Cell. 2005 Jan;120(1):1520.

14 Lewis BP, Shih IH, Jones-Rhoades MW, Bartel DP, Burge CB. Prediction of mammalian microRNA targets. Cell. 2003 Dec;115(7): 787-98.

15 Griffiths-Jones S, Saini HK, van Dongen S, Enright AJ. miRBase: tools for microRNA genomics. Nucleic Acids Res. 2008 Jan;36(Database issue):D154-8.

16 Piva F, Principato G. RANDNA: a random DNA sequence generator. In Silico Biol. 2006; 6(3):253-8.
17 Crooks GE, Hon G, Chandonia JM, Brenner SE. WebLogo: a sequence logo generator. Genome Res. 2004 Jun;14(6):1188-90.

18 Sand M, Skrygan M, Sand D, Georgas D, Gambichler T, Hahn SA, et al. Comparative microarray analysis of microRNA expression profiles in primary cutaneous malignant melanoma, cutaneous malignant melanoma metastases, and benign melanocytic nevi. Cell Tissue Res. 2013 Jan;351(1):85-98.

19 Komina A, Palkina N, Aksenenko M, Tsyrenzhapova S, Ruksha T. Antiproliferative and Pro-Apoptotic Effects of MiR-4286 Inhibition in Melanoma Cells. PLoS One. 2016 Dec; 11(12): 0168229.

20 Ladewig E, Okamura K, Flynt AS, Westholm JO, Lai EC. Discovery of hundreds of mirtrons in mouse and human small RNA data. Genome Res. 2012 Sep;22(9):1634-45.

21 Kafka A, Bačić M, Tomas D, Žarković K, Bukovac A, Njirić N, et al. Different behaviour of DVL1, DVL2, DVL3 in astrocytoma malignancy grades and their association to TCF1 and LEF1 upregulation. J Cell Mol Med. 2019 Jan;23(1):641-55.

22 Gao J, Li H, Liu L, Song L, Lv Y, Han Y. Identification and functional analysis of risk-related microRNAs for the prognosis of patients with bladder urothelial carcinoma. Oncol Lett. 2017 Dec;14(6):7297-303.
Sequence Similarities between Viroids and Seed Regions of Human MicroRNAs 
23 Jima DD, Zhang J, Jacobs C, Richards KL, Dunphy CH, Choi WW, et al.; Hematologic Malignancies Research Consortium. Deep sequencing of the small RNA transcriptome of normal and malignant human $B$ cells identifies hundreds of novel microRNAs. Blood. 2010 Dec;116(23):e118-27.

24 Stern-Ginossar N, Elefant N, Zimmermann A, Wolf DG, Saleh N, Biton M, et al. Host immune system gene targeting by a viral miRNA. Science. 2007 Jul;317(5836):376-81.

25 Grundhoff A, Sullivan CS. Virus-encoded microRNAs. Virology. 2011 Mar;411(2):32543.

26 Morales L, Oliveros JC, Fernandez-Delgado $\mathrm{R}$, tenOever BR, Enjuanes L, Sola I. SARSCoV-Encoded Small RNAs Contribute to Infection-Associated Lung Pathology. Cell Host Microbe. 2017 Mar;21(3):344-55.

27 Zhao Y, Cong L, Lukiw WJ. Plant and Animal microRNAs (miRNAs) and Their Potential for Inter-kingdom Communication. Cell Mol Neurobiol. 2018 Jan;38(1):133-40.
28 Itaya A, Zhong X, Bundschuh R, Qi Y, Wang $\mathrm{Y}$, Takeda $\mathrm{R}$, et al. A structured viroid RNA serves as a substrate for dicer-like cleavage to produce biologically active small RNAs but is resistant to RNA-induced silencing complexmediated degradation. J Virol. 2007 Mar; 81(6):2980-94.

29 Ding B, Itaya A. Viroid: a useful model for studying the basic principles of infection and RNA biology. Mol Plant Microbe Interact. 2007 Jan;20(1):7-20.

30 Machida S, Yamahata N, Watanuki H, Owens RA, Sano T. Successive accumulation of two size classes of viroid-specific small RNA in potato spindle tuber viroid-infected tomato plants. J Gen Virol. 2007 Dec;88(Pt 12):34527.

31 Martín R, Arenas C, Daròs JA, Covarrubias A, Reyes JL, Chua NH. Characterization of small RNAs derived from Citrus exocortis viroid (CEVd) in infected tomato plants. Virology. 2007 Oct;367(1):135-46.
32 Friday D, Mukkara P, Owens RA, Baumstark T, Bruist MF. Processing of Potato dpindle tuber viroid RNAs in yeast, a nonconventional host. J Virol. 2017 Nov;91(24):e01078-17.

33 Friday D, Mukkara P, Owens RA, Baumstark T, Bruist MF. Processing of Potato dpindle tuber viroid RNAs in yeast, a nonconventional host. J Virol. 2017 Nov;91(24):e01078-17.

34 Hill JM, Zhao Y, Bhattacharjee S, Lukiw WJ. miRNAs and viroids utilize common strategies in genetic signal transfer. Front $\mathrm{Mol} \mathrm{Neu-}$ rosci. 2014 Feb;7:10.

35 Delan-Forino C, Maurel MC, Torchet C. Replication of avocado sunblotch viroid in the yeast Saccharomyces cerevisiae. J Virol. 2011 Apr;85(7):3229-38.

36 Chitwood DH, Timmermans MC. Small RNAs are on the move. Nature. 2010 Sep; 467(7314):415-9.

37 Zhang L, Hou D, Chen X, Li D, Zhu L, Zhang $Y$, et al. Exogenous plant MIR168a specifically targets mammalian LDLRAP1: evidence of cross-kingdom regulation by microRNA. Cell Res. 2012 Jan;22(1):107-26. 